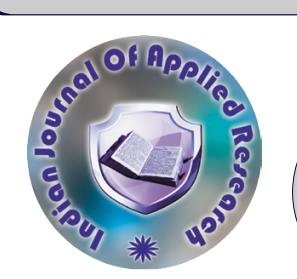

Education

\title{
IMPLEMENTATION OF INTERVENTION STRATEGIES AND ITS EFFECTIVENESS IN THE ACHIEVEMENT OF LEARNING OUTCOMES IN SCIENCE AT UPPER PRIMARY STAGE
}

\section{Dr. Pramila Tanwar}

\author{
Associate Professor DESM, NCERT
}

\section{ABSTRACT}

The research study shows an achievement of students in science studying at upper primary stage. The sample comprises of five Government school students of Delhi. .An Achievement Test has been used for the study. The researcher used $\mathrm{t}$ - test to analyse the data. Main finding of the study reflects a significant difference in the Achievements of students in science after given that intervention strategies based on hard spots identified during field study.

\section{KEYWORDS : Science, upper primary, pre - Achievement test, learning outcomes, survey method}

\section{INTRODUCTION}

Science is a dynamic field which covers knowledge on ever-new domains of experience based on inquiry born out of natural curiosity, logical reasoning and experimentation (Laurillard, 2013). Science education at the upper primary stage should provide a gradual transition from environmental studies of the primary stage to elements of science and technology. Science concepts to be taught at this stage should be chosen so as to make sense of everyday experiences without a rigidly inductive approach, ensuring that a majority of activities and experiments are inexpensive and use readily available materials, so that this core component of science curriculum can be implemented in all schools irrespective of inadequate infrastructure. Experience has shown that experiment-based science teaching is possible and viable under diverse conditions and with a very reasonable demand on resources (Position paper on teaching of science, 2006).

During the last two decades, various educational surveys, achievement data indicate that learning achievements of students in Science at the Upper Primary Stage are not up to the expected level in many states of India (Annual Status of Education Report, ASER, National Achievement Survey, NAS, 2017). Learning outcomes in Indian Upper Primary Education are consistently low. NAS and ASER have echoed similar findings. ASER (ASER Centre 2016), based on a sample of schools in all rural districts, shows that $75 \%$ of grade 8 children from rural India cannot understand simple basic Science concepts. This learning gap worsens with age. For example, the percentage of students who can clearly understand a science question reduced from $68 \%$ in 2010 to $43 \%$ in 2016 . NAS-2017 results showed that there is a gradual declined in science learning at upper primary stages. Hence, there is a great need to explore this area. Though some studies have been carried out to assess the learning outcome of students in subject specific categories like the ASER study reports for the states in different years, different cycles of NAS by NCERT, studies by SCERT etc, but none of the studies give a unique measurement to quantify the learning outcome of the students. Hence it has been felt that there is a need to have a comprehensive index to measure the outcome of learning and consequently filling up the gaps by implementing suitable intervention strategies.

Therefore the pertinent question is how scientifically to assess 'Learning Outcome' in a measurable index, understanding the curriculum by a student as one moves to higher grade and also to assess the teaching methodology or rather the outcome of the methodology because there is a general perception in education that as a student moves to a higher grade, he/she has completed the understanding of the preceding grade, while assessing the learning outcome of a student of grade VIII, it may be assumed that he/she has learnt the curriculum of $\mathrm{V}, \mathrm{VI}$ or $\mathrm{VII}^{\text {th }}$ grade and has then moved to the higher grade. However, students seem to harbour a number of misconceptions in the different subjects indicating that if a student develops a misconception in a lower class, then it is more likely to continue in higher classes too without getting corrected (Vyas, 2013).

The achievement of the educational objectives through transformation, endeavour, relating to the life, needs and aspirations of the people and thereby make it a powerful instrument of social, economic and cultural, a fivefold program was suggested, that included, relation between education and productivity, strengthening social and national integration through education programs, development of social, moral and spiritual values, and modernization of society by awakening awareness and building essential skills (The Kothari Commission 1966). Disparities in education also contribute a great deal to the persistence of massive inequalities in Indian society such as those of grade, caste and gender (Dreze, 2003). There is a need to develop the direct measures of learning outcomes so that the limitations of current proxies for quality of learning as well as teaching can overcome by analysis feedback on students' performance (Tremblay et al., 2012). There also exists a negative correlation between usage of guide books, correction and explanation of homework, low interest of parents in children's education, low educational level of mothers and students learning outcomes (Bahuguna, 2011). Indifference or discrimination of teacher, school policies, medium of instruction, and excessive reliance on homework where parents are not educated and cannot provide an adequate support system perpetuate the disadvantage of low levels of skill development among economically poor and socially disadvantaged groups and girls especially in the rural areas are either denied access or are failing to complete even five years of basic education. But an effective teacher uses several methods of teaching to reach each student thereby applying teaching skills, professional characteristics and classroom climate as well. It contributes in the variation of pupils' progress.

According to the census 2001 data, it is disturbing to note that though there has been an improvement in the enrolment rates, the dropout rate is still high (Gross Dropout Rate-40.7percent) (Desai and Thorat, 2010). In 2016, the National Learning Achievement Surveys conducted by Ministry of Human Resource Development, Government of India found that children from historically disadvantaged and economically weaker sections of the society, ruralurban differences and students from general, SC, ST and OBC categories exhibit significantly varied learning outcomes and appropriate measured are taken to stop the decrement in the dropout rate and to improve retention of the students from the socially and economically backward communities. Consequently different states and UTs have taken different measures to enhance and ensure quality learning outcomes via enhancing early grade reading, writing and arithmetic during school. However the poor learning outcomes continue to be a matter of concern.

Learning Outcomes at the Elementary Stage was developed by NCERT at the national level for teachers, teacher-educators, educational administrators, as well as for parents to enhance the quality of learning in schools and to enable teachers to ascertain learning skills more accurately to provide learning Opportunities to all students including children with special needs. The class-wise (from classes I to VIII) expected learning outcomes have been developed for subjects such as Environmental Studies, Science, Mathematics, Social Sciences, Hindi, English and Urdu to help all stakeholders to make their efforts; in the right direction. Based on the Learning Outcomes, National Achievement Survey (NAS) was conducted throughout the country in 2017 for Classes 3, 5 and 8 in government and government aided schools. The learning levels of 2.2 million students from 1 , 10,000 schools across 701 districts in all the 36 States/UTs of the country were assessed and results showed learning outcomes account for $36 \%$ of all indicators. There is positive interactions between teacher and child are minimal. In less than a third of all classrooms did the 
student ask questions and less than $20 \%$ of teachers smiled or joked with the students (Desai et al., 2008) while negative perception of their own learning and the experience of school results in drop outs or poor performance (Bhattacharjea et al., 2011). The Action Plan 2017-19 of NITI Aayog emphasised to focus on improving learning outcomes by introducing a state-level School Education Quality Index (SEQI) to 'institutionalise the focus on improving education outcomes' and provide insights into states' strengths and weaknesses.

In India, Upper primary education lasts three years from grades 6-8 (ages approximately 11-14), the number of subjects taught increases and becomes more specialist than at primary levels. As for primary level, the Draft National Education Policy proposes a wider range of subjects at upper primary level, including potential foci on 'critical issues' and 'moral reasoning' between grades 6-8 (Ministry of Human Resource Development, 2019) but achievement gaps between the higher and lower-achieving learners become more evident as curricula become more ambitious at upper primary level. As one study on such overambitious curricula demonstrates, 'paradoxically, learning could go faster if curricula and teachers were to slow down' (Pritchett and Beatty, 2012).

NAS 2017 reveals that in class VIII on an average only 34 percent of students in Delhi are responding correctly to the questions in science and only 78 percent of children understand what teachers say in the classroom. After the publication of the results of National Achievement Survey conducted by NCERT, it was felt that need based interventions should be conducted in the low performing Districts of Delhi in the area of science at upper primary stage. Keeping this in view, the Department of Education in Science and Mathematics take up a research study to prepare, implement and assess effectiveness of intervention strategies in selected schools. The main objectives of the research study are:

i. To assess the learning level of students in science at upper primary stage.

ii. To analyse the factors hindering the achievement of expected learning outcomes in Science designed by NCERT at upper primary stage.

iii. To develop need based interventions for the teachers and students to achieve expected learning outcomes in science at upper primary stage.

iv. To study the effect of the need based interventions in achieving expected learning outcomes in science at upper primary stage.

This study will help teachers to focus more on teaching-learning process so as to improve the learning levels of students for quality education in schools throughout the nation.

\section{METHODOLOGY:}

A field survey method was carried out to study and analyse the expected learning outcomes of students in Science at Upper Primary Stage where the following procedures were adopted.

1. Identification of schools to assess the learning level of students in science at upper primary stage: Based on the report of National Achievement Survey, 2017, conducted by NCERT, from the identified and selected five low performing districts of Delhi in the area of Science, 20 students from each five schools were randomly chose to carry out the study as shown in the table.

\begin{tabular}{|c|c|c|c|}
\hline District & Zone & School Name & $\begin{array}{c}\text { Location of } \\
\text { Selected Schools }\end{array}$ \\
\hline East Delhi & 02 & Sarvodaya Bal Vidayalaya & Mayur Vihar, Phase II \\
\hline North East & 06 & Sarvodaya Kanya Vidayalaya & Shastri Park \\
\hline $\begin{array}{l}\text { South } \\
\text { Delhi }\end{array}$ & 23 & $\begin{array}{l}\text { Sarvodaya Bal Senior } \\
\text { Secondary Vidayalaya }\end{array}$ & Qutub, Mehaurli \\
\hline $\begin{array}{l}\text { Central } \\
\text { Delhi }\end{array}$ & 27 & $\begin{array}{l}\text { Government Girls Senior } \\
\text { Secondary School }\end{array}$ & $\begin{array}{c}\text { Pataudi House, } \\
\text { Darya Ganj }\end{array}$ \\
\hline West Delhi & 17 & $\begin{array}{l}\text { Government Boys Senior } \\
\text { Secondary School }\end{array}$ & Punjabi Bagh \\
\hline
\end{tabular}

2. Analysing the factors hindering the achievement of expected learning outcomes in Science designed by NCERT at upper primary stage: Through detail literature reviewing by researchers related to the learning outcomes in Science at Upper Primary Schools, a questionnaire for each students and teachers were framed highlighting areas of difficulties in Science chapter(s)/section(s) that may be facing by teachers in teaching and students in learning. Besides questionnaire, a free and frankly focus group discussion with few selected students were held in order to know more details about the hard-spots assessing the ground reality in perceiving the expected learning outcomes by students. Also, a Pre Intervention-Achievement test was conducted based on simple basic concepts in Class VIII Science so that the research study can familiarise with and help in assessing the expected learning outcomes developed by NCERT.

3. Development of need based interventions for the teachers and students and implementation of the same to achieve expected learning outcomes in science at upper primary stage: After analysing and finding out the hard-spots that hinder the achievement of expected learning outcomes in Science, a workshop was conducted to develop need based training modules for Class VIII Science and consequently develop need based interventions for teachers and students. Subsequently, a five days training was carried out at DESM, NCERT along with teachers of those identified low performing schools where detail instructions of how to implement those need based interventions in schools so that expected learning outcomes in Class VIII Science may achieve.

4. Evaluation of the effect of the need based interventions in achieving expected learning outcomes in science at upper primary stage: Once the schools implemented the developed intervention strategies, a post achievement test was conducted in each identified schools where two grouped were divided, one experimental group was given intervention strategies and the other group not given intervention strategies served as control of the research study. The obtained results were used to evaluate the effectiveness of those developed need based interventions showing how far these intervention strategies can improve in achieving expected learning outcomes in Science developed by NCERT.

\section{RESULTS \& DISCUSSION :}

From the survey and studies conducted through schools, the following results were obtained.

1. During the pre intervention test, all five low performing schools show poor results, where out of 15 marks test, the percentage of the average score obtained by students from each schools ranges from $24.66 \%$ (Govt. Girls Senior Sec. School, Darya Ganj) to 57.66 \% (Sarvaodaya Bal Senior Sec. School, Qutub, Mehrauli) (Fig.3) indicating the correlation results reported by NAS, 2017.

2. From the assessment and analysis of the test results by schools (Fig. 1), factors which may result in hindering the performance of the students like hard-spots, difficulty in understanding the language of the concepts of Class VIII Science, etc. were identified so that further necessary need based intervention could be implemented to improve the learning levels of students in schools.

3. In order to implement need based interventions for teacher as well as students, modules were developed at DESM, NCERT by experts and resource persons where each identified hard spots and difficulties in Science conceptual, understanding the language written were simplified or added elaborate points focusing more on the day to day experimental based approach that may be helpful for both teachers and students in achieving the expected learning outcomes in Science were dissipated to Science teachers of selected low performed schools through proper training.

4. From the implementation of need based interventions, all five low performing schools shown improvement in the Post-Intervention Test scores from both Pre and Control Tests (Fig. 2) where Percentage of average Tests' scores increased from $24.66 \%$ to $67.66 \%$ for Govt. Girls Senior Sec. School, Darya Ganj ; from $57.66 \%$ to $84.83 \%$ for Sarvaodaya Bal Senior Sec. School, Qutub, Mehrauli; from $56.66 \%$ to $82.33 \%$ for Sarvodaya Bal Vidayalaya, Mayur Vihar-Phase II; from $46.16 \%$ to $76.33 \%$ for Sarvodaya Kanya Vidayalaya, Shastri Park; from $57.33 \%$ to $83.33 \%$ for Govt. Boys Senior sec. School, Punjabi Bagh; therefore verifying and validating the successful implementation of need based interventions developed at DESM, NCERT by respective schools. Due to the implementation of need based intervention strategies of the expected learning outcomes in the selected low performed schools, the results show the overall improvement of approximately $30 \%$ increase in Post Intervention from the Pre Intervention strategies (Fig. 4) while only $5 \%$ improvement in the Control Achievement Test from Pre Intervention-Achievement Test scores. 


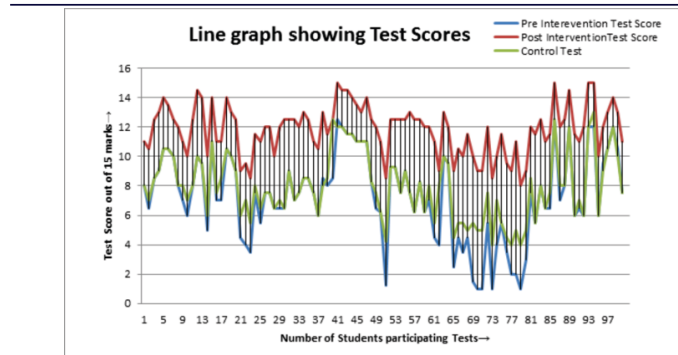

Figure 1: A line chart showing Marks scored by each student (1100) in Pre, Control and Post Intervention Tests of all five Schools.

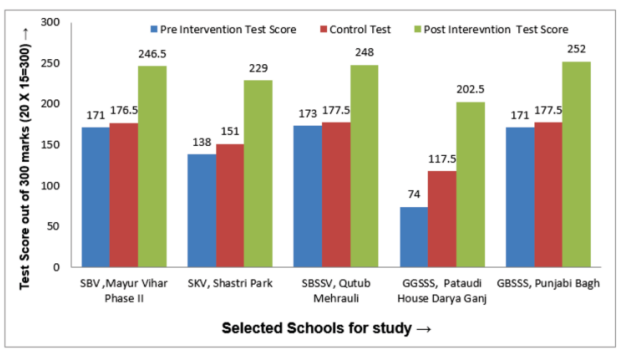

Figure 2: A bar graph representing the sample student (20) performance in 15 marks Tests of each selected Schools

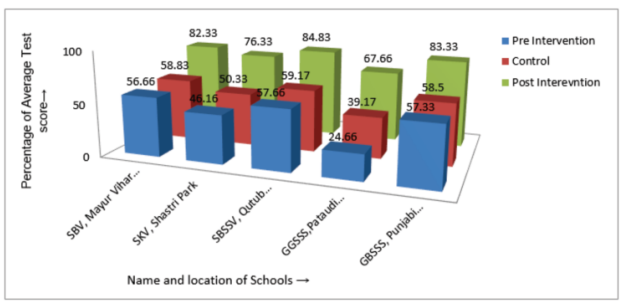

Figure 3: A bar chart showing overall Percentage (\%) of the average Test scores for each School

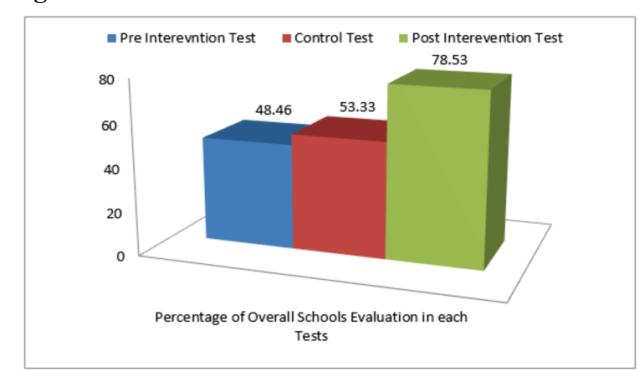

Figure 4: A graph showing overall evaluation of all five schools in the pre, control and post implementation of need based interventions

\section{CONCLUSIONAND SUGGESTIONS:}

The present study was aimed at studying and assessing the causes and factors that resulted in low performance of selected schools in the expected learning outcomes especially in Science subject at Upper Primary Level (Class VIII in this study) subsequently developing the need based intervention strategies thereby implementing those developed strategies to speed up the expected learning outcomes in the selected low performing schools. Familiarisation with the expected learning outcomes in Science developed at NCERT by teachers is must in order to focus more on teaching-learning process so as to improve the learning levels of students for quality education in schools. However, the study in low performing schools revealed that the students' learning outcomes in Science required more experimental base approach to enable the students in clear understanding the basic concepts of Science so that they would easily familiarise Science when upgraded in higher classes.

From the study, it was evident during observation in focus group discussions with students that in class those students who had a hand on activities /projects/ assignments/experimentations involving basic Science in day to day life reported that it helped them in better learning, remembering and understanding the concept of those hard-spots in Science. The study also showed that nearly one-fifth of the teachers who taught Science in Class VIII were familiarised with the NCERT developed expected learning outcomes in Science which may be one factor that hinder in achieving the expected learning outcomes in the schools. This research study helped in assessing the actual ground reality of learning level of students in Science at Upper Primary Level and also in finding and analysing the causal factors that hindered and the necessary intervention strategies that may expedite the achievement of expected learning outcomes in Science designed by NCERT for Class VIII Science in low performing schools.

Astonishingly, when those low performed schools implemented the need based intervention strategies developed by DESM, NCERT after providing the proper training to Science teachers of the schools, it was found that the intervention strategies based on teaching-learning inputs given to the students was directly proportional to the better expected learning outcomes of the students where overall increased of approximately $30 \%$ was seen during the evaluation from the PreIntervention Achievement Test to the Post-Intervention Achievement Test. This improvement in the expected learning outcomes after proper implementing intervention strategies implies that it can bring a change in the Science learning outcomes ensuring quality education at Upper Primary Stage.

\section{REFERENCES:}

1. ASER Centre (2016). Annual Status of Education Report (ASER) and National Achievement Surveys (NAS): a comparison. Pratham Education Foundation. https://bit.ly/2TJTDk6.

2. Ankit Vyas, (2013). Low Learning Outcomes in Primary Schools in India. International Journal of Management \& Behavioural Sciences (IJMBS). Vol. 05, ISSN 2278-5671

3. Bhattacharjea, Suman, Wilima Wadhwa, and Rukmini Banerji (2011). "Inside Primary Bchools." Pratham Mumbai Education Initiative, ASER (Assessmet Survey Evaluation Research)

4. Bhattacharya, R., \& Govinda, R. (2011). Education For All-Towards Quality with Euity. Ministry of Human Resource Development, Government of India . National University of Educational Planning and Administration.

5. Desai, Sonalde, Amaresh Dubey, Reeve Vanneman, and Rukmini Banerji (2008) "Private Schooling in India: A New Educational Landscape." India Policy Forum, Global Economy and Development Program, The Brookings Institution 5 (1): 1-58.

6. Laurillard, D., (2013). Teaching as a design science: Building pedagogical patterns for learning and technology. Routledge.

7. Ministry of Human Resource Development (2019: 98-100). Draft National Education Policy. New Delhi:Pritchett and Beatty (2012). Pritchett, L and Beatty, A (2012) The Policy. New Delhi:Pritchett and Beatty (2012). Pritchett, L and Beatty, A (2012) The
Negative Consequences of Overambitious Curricula in Developing Countries. CGD Working Paper 293. Washington, DC: Centre for Global Development.

8. Available online at: https://www.cgdev.org/publication/negative-consequencesoverambitiouscurricula-developing-countries-working-paper-293

9. Tremblay, K., Lalancette, D., \& Roseveare, D. (2012). Assesment of Higher Education Learning Outcomes. OECD (organisation for economic co-operation and development). 